\title{
LA HISTORIA CONTEMPORÁNEA DE ESPAÑA DE JUAN VALERA (SU CONTINUACIÓN DE LAFUENTE), COMO ARTEFACTO LITERARIO
}

\author{
Enrique Serrano Asenjo \\ Universidad de Zaragoza \\ jeserra@unizar.es
}

Palabras clave: Juan Valera, romanticismo español, historiografía decimonónica, Hayden White.

KEY WORDS: Juan Valera, Spanish Romanticism, 19th Century Historiography, Hayden White.

El 3 de febrero de 1851, el joven Valera, que buscaba el triunfo de sus ilusiones en la capital del reino, le escribía a su madre sobre una idea largo tiempo instalada en su imaginación ${ }^{1}$. Se trata de un proyecto bien audaz, a saber, escribir la historia de los reyes de la casa de Austria, desde la toma de Granada a la guerra de Sucesión. El plan incluía una introducción filosófica y hasta un epílogo sobre los Borbones. Don Juan tenía muy claro el modo de plantear la empresa: "yo quisiera escribir con mucha copia de datos y de filosofía, dando a todo un pensamiento capital que sirviese de base y diese unidad y belleza a mi obra" (Correspondencia I 142). No llevó a efecto su deseo, aunque toda su vida siguió interesándose por la Historia. Lo demostró en las vísperas del centenario de su muerte la publicación del volumen Obra histórica, editado por Romero Tobar. A más de poner de relieve una faceta de la producción valeresca a la fecha poco explorada por los estudiosos, el logro principal del libro consiste en que el editor establece la parte que se puede adjudicar a Valera en la continuación de la Historia General de España de Modesto Lafuente, tarea que el novelista llevó a cabo junto a Andrés Borrego y a Antonio Pirala (Azaña 205ss.; Rújula LXV-LXIX). Sin lugar a dudas, el extenso trabajo preparado en

${ }^{1}$ El presente trabajo se inserta en el marco del proyecto de investigación HUM 2005/06063, del Ministerio de Educación y Ciencia. 
esta ocasión por el creador del doctor Faustino supone, con mucho, su escrito histórico más destacado; pero no solo eso, porque nos encontramos ante un documento de primer orden en su producción, con referencias destacadas a su estética, por ejemplo, o a un componente tan significativo de su biografía como el romanticismo.

Aquí se sugiere una lectura de dicha continuación a partir de los planteamientos de Hayden White, quien en un conocido ensayo aborda el texto histórico en tanto que artefacto literario. White considera que: "la historia — el mundo real tal como evoluciona en el tiempo - cobra sentido de la misma manera en que el poeta o el novelista tratan de darle sentido, es decir, dotando a lo que originalmente parece ser problemático y misterioso del aspecto de una forma reconocible porque es familiar" ("Texto" 138). Más concretamente presenta las obras de historia como amplias estructuras simbólicas o metafóricas que asemejan los hechos contados a alguna forma establecida en la tradición cultural y que, por tanto, ya es conocida por los individuos insertos en ella (125; cfr. Gullón 232).

Vayan por delante las preocupaciones menos científicas y más artísticas que asaltan a Valera ante la magna labor que le espera y que expresa así a su colaborador Borrego en carta fechada probablemente en 1881: "Es indudable que una historia ya universal de todo el género humano, ya general de un reino, nación o comarca, ya general también de una ciencia, religión o doctrina, ha de considerarse como conjunto armónico y en cierto modo simétrico, donde sean proporcionadas las partes" (Correspondencia III 298). Y al poco insiste: "Si por algo los hemos de vencer ha de ser porque en el conjunto de lo que escribamos se comprenda mejor el todo, como un bello cuadro sinóptico, y porque en el estilo, (...) acierte a pintar en pocos rasgos, certeros y enérgicos, caracteres, tendencias, fines y resultados..." (299). Es obvio que don Juan no equipara la tarea del poeta a la del historiador (cfr. Sotelo Vázquez 50), pero sí encuentra semejanzas y lo ratifica en distintos títulos de su trayectoria.

Así por ejemplo en su "Plan de una historia de España y Portugal", entre 1868 y 1878, había señalado: "creemos que el historiador debe, como el poeta, aspirar a esta unidad de acción, por ser el más importante de los requisitos artísticos" (585). Pero es que en 1900, al reseñar la biografía del diplomático Cristóbal de Moura que su amigo Alfonso Danvila acababa de publicar, retoma una idea cuyas primeras manifestaciones fueron aquellas quimeras de juventud sobre los Habsburgo ya citadas: "Una narración histórica, lo mismo que un poema y lo mismo que una novela, puede considerarse como obra de arte, con unidad de acción en su conjunto" (Don Cristóbal 801). Y aquí es donde Valera y White pueden acercarse.

Al proseguir la obra de Lafuente, Juan Valera se encarga de narrar la vida literaria española en el decenio que sigue a la muerte de Fernando VII, es decir, el momento de auge de la llamada revolución romántica; $y$, por otro lado, se ocupa de la política entre 1843, cuando es proclamada la mayoría de edad de Isabel II, y 1860, en pleno gobierno de la Unión Liberal. Pues bien, el hilo conductor del cúmulo de acontecimientos relatados por el historiador, la forma acreditada por la tradición cultural que facilita la comprensión de la compleja realidad referida o, si se prefiere, la unidad de acción que Valera tenía siempre presente cuando de hacer historia se trataba, aquí es el resurgimiento de España, o mejor: su renacimiento tras la dilatada postración previa. 
Veamos cómo se concreta esta trama. El comienzo del reinado de Fernando VII significa "el periodo más bochornoso de la triste historia de nuestra decadencia" ("Continuación" 13). Ahora importan menos las raíces de la misma, que Valera sitúa en el siglo XVI (cfr. Sáinz Rodríguez 117), que su percepción de que desde la muerte del Deseado el país "progresa, adelanta, gana mucho en todo" ("Continuación" 32). Ello supone un cambio completo en todas las facetas de la vida española, cambio que el narrador principalmente explica por tres razones: a) apenas era posible empeorar desde la situación que el monarca había dejado; b) las ventajas ofrecidas por el mero contacto con la civilización europea; y c) la venta de los bienes del clero trajo consigo el aumento de la riqueza al salir al mercado grandes extensiones de tierra antes en poder de manos muertas (143).

El caso es que la faceta del país donde mejor se muestran los logros o, al menos, la faceta a la que más atención prestará el escritor a este respecto es la literatura. Y es que para Valera "los conflictos sociales se hacen más evidentes si son contemplados al trasluz de las experiencias artísticas y de las transformaciones económicas y culturales que experimentan las sociedades humanas" (Romero Tobar XXXIX). La presencia de lo económico en el proceso expuesto tiene el protagonismo que se advertía en el párrafo anterior con el énfasis sobre la desamortización, pero en el texto destaca más que nada la larga exposición sobre las letras en los comienzos de la edad contemporánea en España o, lo que es lo mismo, el pormenorizado análisis del romanticismo que realiza el diplomático novelista.

La explicación del "singular florecimiento" ("Continuación" 32) literario acaecido desde 1833 resulta coherente con las causas que contribuyen al progreso global del reino e incluye algunos matices añadidos: "La propia vida interior del espíritu de España, fomentada por la libertad, fue la causa principal de este florecimiento; pero contribuyó también no poco el aluvión de ideas traídas de país extranjero por la facilidad de comunicaciones (...) y la vuelta de muchos emigrados" (41). Además de constatar la perspectiva de nacionalismo liberal que impregna toda la labor intelectual de Juan Valera y desde luego sus páginas historiográficas (cfr. Beltrán Almería 18), aquí importa sobre todo subrayar la perspicaz y temprana valoración del regreso de los emigrados como factor fundamental en la llegada de las nuevas tendencias, línea que, como es sabido, terminará de desarrollar espléndidamente otro expatriado como Vicente Lloréns (pássim).

Aunque no es ocasión de plantear un asunto de tanta enjundia como las relaciones de don Juan con el fenómeno romántico (Bermejo 164 ss.; Abad 67-70), conviene hacer constar que "manifiesta poseer una visión mucho más matizada del romanticismo que la que había expuesto en sus escritos juveniles. Ahora lo considera como la atmósfera que había dado vida a los grandes cambios y conflictos experimentados por la España del segundo tercio del siglo" (Romero Tobar LXV) ${ }^{2}$. Y así distingue las transformaciones

2 Vale la pena, en todo caso, tener presente la cita siguiente de su artículo de 1854 "Del romanticismo en España y de Espronceda": "El romanticismo, por tanto, no ha de considerarse hoy día, como secta militante, sino como cosa pasada y perteneciente a la 
que se producen en la ubicación del escritor en la sociedad, un escritor en trance de hacerse profesional, que ha de pelear con las reglas del mercado y buscar a brazo partido al receptor-consumidor, con frecuencia en el palenque de los periódicos. Es la situación irreversible que Valera y sus coetáneos han recibido, y que, en rigor, no había cambiado tanto desde la década de los años treinta: "tenemos que repetirlo con frecuencia (...) el público se encerraba entonces en estrecho círculo, y el entusiasmo literario era efímero y como por moda. Los autores no hacían más que lamentarse de no ser oídos o leídos. En Larra era esta una idea fija..." (“Continuación" 118). Y en Valera también lo será, a pesar del papel muy escaso que concede a Fígaro en su relato y que es el principal lastre del canon propuesto, un canon, por otro lado, razonablemente actual en sus demás consideraciones.

El historiador literario que es Valera en el primer tramo de su relato nacionaliza la revolución romántica, a la vez que disminuye sus señas más rupturistas al plantear la existencia de un romanticismo antiguo español y otro moderno ${ }^{3}$. En efecto, establecerá que en los siglos XVI y XVII hubo un romanticismo "castizo", no bien valorado por la posteridad ("Continuación" 48 y 67), con el que confluye el más reciente ${ }^{4}$. La obra del duque de Rivas le parece la máxima expresión de la fusión de ambos, pues "supo combinar el moderno romanticismo extranjero con el ser romántico por excelencia de nuestra antigua y propia literatura" (53). Más precisamente, Don Álvaro o la fuerza del

Historia. El romanticismo ha sido una revolución, y sólo los efectos de ella podían ser estables. Entre nosotros vino a libertar a los poetas del yugo ridículo de los preceptistas franceses y a separarlos de la imitación superficial y mal entendida de los clásicos, y lo consiguió. Las demás ideas y principios del romanticismo fueron exageraciones revolucionarias, que pasaron con la revolución y de las cuales, aun durante la revolución misma, se salvaron los hombres de buen gusto" (9).

${ }^{3}$ Menos clara que la distinción anterior resulta la que establece entre un romanticismo "histórico, épico-popular o legendario" y otro "subjetivo o byroniano" ("Continuación" 62), aunque parece legítimo sugerir que en parte se basa en ella.

${ }^{4}$ Sobre la naturaleza del romanticismo dice: "venido sin duda de fuera, pero que se injertaba fácil y rápidamente en el árbol fecundísimo de nuestra antigua literatura nacional, épica y dramática, que se unía, cobrando vida castiza y vigor lozano, a nuestra poesía más espontánea y popular, al teatro y al romancero" ("Continuación" 49). Vale la pena comparar la propuesta valeresca de un romanticismo español de primera hora en el Quinientos y el Seiscientos con este planteamiento posterior de uno de los mejores críticos españoles del siglo XX: "La originalidad del arte clásico español está tocada de lo que podemos llamar modernidad, de igual modo que la literatura española de los siglos de oro está empapada en lo que ya puede llamarse romantismo. Antes de que este nombre se invente, nuestros poetas románticos del siglo XVII han encontrado su movimiento y su color. Cuando los padrinos alemanes de la nueva edad literaria descubren a Calderón y a Lope, ya encuentran realizadas en ellos las novedades a que aspiran" (Díez-Canedo 459). Con un planteamiento de autorreivindicación, Onís hace constar de forma más escueta que "nuestra comedia clásica es el primer teatro popular y romántico de Europa” (161). 
sino, al que dedica un comentario detenido, consiste en "el más acabado modelo de nuestro teatro romántico castizo" (57). Esta valoración en realidad significa la propuesta de romanticismo ideal para Valera, es decir, equilibrio entre las nuevas doctrinas foráneas y la tradición española, y todo ello admirablemente resuelto con unos caracteres nobles, bien que sobrepasados trágicamente por unas circunstancias encadenadas de modo "natural y verosímil" (54)

A pesar del paso de la edad y del enfoque "domesticador" que se acaba de señalar, don Juan reconoce algunos defectos en el movimiento que abre la época contemporánea en las letras españolas. El problema fundamental y acaso su mayor baza paradójicamente coinciden:

un estro indómito y fundado en cortísimo saber, con el cual, cuando se acierta, es que se adivina, por donde tiene el acierto un no sé qué de maravilloso que raya en lo sobrenatural, y muchas veces, cuando se delira, es porque se ignoran o se reciben en la mente, enmarañadas y confusas, mil ideas nuevas, que vagan por el aire... (87).

La ironía valeresca salpica una apreciación sobre la que vuelve en diversos pasajes de su trabajo en la medida en que le afecta (p. e. 44). No es casualidad, evidentemente, que él posea una formación muy sólida y, desde luego, clásica, a la que no escapan sus escritos, como es lógico y sea del modo que sea, desde sus informales cartas familiares a los ensayos más eruditos sobre cualquier particular que traten.

Si hay un nombre que encarna las luces y las sombras del fenómeno en cuestión es José de Espronceda, a quien personalmente trató Valera en su adolescencia junto a otros ilustres conmilitones como Miguel de los Santos Álvarez, según recuerda en diversas ocasiones, siendo una de las más llamativas la noticia autobiográfica que envía a Ramírez de las Casas-Deza en 1863 (Correspondencia II 33). El caso es que el creador de Félix de Montemar se malogró ("Continuación” 123); pero no por haber muerto joven, sino más bien por un exceso de orgullo y de ignorancia, de la que, además, hacía alarde. Y sin embargo, cuando prescinde de la presunción romántica alcanza sus logros más altos, como el tercer cuadro de El estudiante de Salamanca, siempre según el lector interesado que es don Juan: "Difícil también será hallar en toda nuestra literatura, tan sobresaliente

${ }^{5}$ El planteamiento de Valera respecto del romanticismo me parece comparable a su postura política en defensa de los partidos medios, que es la base sobre la que se creó El Contemporáneo y a la que él se sumó, aunque probablemente cabe trasladarla al resto de su currículum como hombre público y, desde luego, escritor: "doctrinas no radicales, sino limitadas por las circunstancias, conciliables con el elemento tradicional y en manera alguna adversas a ciertas instituciones seculares, que arrancan de las entrañas mismas de la historia patria, por donde conviene no desarraigarlas sino afirmarlas más cada día injertando en ellas, como en tronco fecundo, todas las conquistas de la civilización moderna, las cuales pueden dar así, con mayor seguridad y prontitud, sazonados frutos" ("Continuación" 485-6). La repetición de la imagen botánica del injerto en este pasaje y en el citado en la nota anterior resulta una casualidad significativa. 
en lo dramático, nada que supere las escenas de este cuadro" (131). O bien, dentro del disparatado plan de El Diablo Mundo, reconoce que "se contienen, aisladamente considerados, los trozos más bellos y magníficos de poesía que hay en castellano y tal vez en lengua alguna" (133). El escritor consigue que sus receptores se pregunten con pesar hasta dónde no hubiera llegado la obra de Espronceda sin las limitaciones indicadas, si con ellas llegó tan alto.

Sea como fuere, una ponderación no muy distinta expone Valera en torno al tópico de la finalidad de la obra literaria en el marco romántico. "La nueva escuela romántica tuvo la ambición de que la poesía fuese docente; pero la tuvo de manera tan vaga que, en lo práctico, se puede afirmar que seguía la regla del arte por el arte más conforme en esto con la poética de Aristóteles bien entendida" (55). Esta regla de oro fue respetada por la "primitiva escuela romántica" (84) y por sus continuadores, como por ejemplo Hartzenbusch, y lo aprecia más desde que "el prurito de los problemas" (55) entrampa a la gente de pluma. Ante esta situación y sin dejar de mirar hacia el pasado inmediato objeto de estudio, una vez más en su trayectoria realiza una declaración de principios:

La poesía en sí tiene un fin altísimo, que es la creación de la belleza; y como la belleza, creada y luego contemplada y comprendida, mejora y ensalza las almas de los hombres, sólo de aquí resulta que el poeta (dado que queramos adoptar el término algo ampuloso de los románticos) tenga que cumplir una soberana y benéfica misión para con su patria y para con la humanidad entera (125; cfr. Rubio Cremades 160-3).

Ni con el engolamiento romántico, ni con sus extravagancias transigirá Valera (“Continuación" 87), y en cuestión tan decisiva en su percepción del oficio de escribir como es el objetivo de la literatura no termina de deshacerse de cierta reticencia hacia la "moderna escuela" con sus iniciales pretensiones pedagógicas.

Pues bien, a pesar de todo ello, la valoración última no puede ser más entusiasta: "no ha habido nunca en España período más brillante ni más fecundo para las letras patrias, para la poesía en su más lato sentido, que el que, si no se encierra en los diez años de 1834 a 1844, los tiene como núcleo o foco" (52). Al margen de que la escasa perspectiva histórica distorsionase un tanto el juicio del agudo lector que fue don Juan, lo cierto es que llama la atención notablemente que, contando con los puntos débiles que advierte en la escritura romántica, pueda pronunciarse de la forma indicada. Pero lo cierto es que su visión global de las letras de los años treinta y cuarenta, calificada de "primavera fecunda del ingenio español" (60), solo es matizada desde planteamientos ajenos a lo estrictamente literario, lo que a la postre representa una forma de confirmación de la excelencia apuntada. Por un lado, señala el reconocimiento escaso que fuera se hace de los autores españoles por meras razones políticas, "todavía aquella primavera del ingenio español produjo flores lozanas, bellísimas e inmortales; y, el día en que la nación se eleve políticamente a mayor altura, será estimado todo esto, y singularmente nuestra poesía, a par de la contemporánea de otros pueblos poderosos y más felices" (95); y por otro lado, incluye el factor temporal para limitar el florecimiento encomiado: "una anticipada primavera (...) Aquel amor y aquel favor que a las letras y singularmente a la poesía se consagraban, eran efímeras. Con la fiebre romántica nacieron y con ella pasaron" (114, 
destacados míos). Evidentemente, además, destaca en sus palabras la constante imagen "primaveral", que en definitiva no deja de ser un renacimiento.

Al terminar Valera su exposición sobre el romanticismo, justifica el amplio espacio dedicado al asunto por ser la manifestación coetánea más brillante del ingenio nacional y por su relación con la política en unos términos curiosos. El auge literario al parecer refrenó la revolución, pues los políticos progresistas al escribir versos se convertían en reaccionarios: "Muchas causas contribuían a esto, no siendo la menor la consideración de nuestra grandeza nacional cuando teníamos Inquisición y fanatismo, y de nuestra postración, a pesar de la libertad política y de cierta tolerancia religiosa y filosófica" (136). El historiador amateur discrepa por completo de tal supuesto, pues piensa que la postración precisamente era fruto del fanatismo y el absolutismo. Por consiguiente, la ausencia de ambos significa el comienzo del fin de la misma. El optimista permanente, de raíz ilustrada, que fue Valera (Romero Tobar XXXII; Amorós 141; Cuenca Toribio 103), afronta en su relato la superación de la decadencia, superación cargada de nubarrones como la guerra carlista, pero que llega de la mano de la libertad. Es el origen doloroso y estimulante de la España a la que él pertenece.

Valera no acaba de decidirse sobre el posible talante pedagógico de la Historia ${ }^{6}$, composición mental muy definitoria de su carácter sutilmente dialéctico (Amorós 143), que en este caso puede deberse al lugar "intermedio" que la disciplina ocupa entre lo científico y lo literario, o a que no terminó de ocuparse firmemente del asunto por el motivo que sea. A mi modo de ver, a White le asiste la razón cuando señala que "toda narrativa histórica tiene como finalidad latente o manifiesta el deseo de moralizar sobre los acontecimientos de que trata" (Contenido 29). Pues bien, José F. Montesinos vio en Juan Valera a un moralista, entendido a la francesa, como un observador de la conducta de los hombres (191), y a aplicar esta idea al presente trabajo contribuye desde la dedicatoria a don Antonio Rodríguez-Moñino al frente de su clásica monografía. Allí expone la idea de fabulación del cordobés, que pretendió "aproximar la realidad a una idea iluminadora que le diese sentido" (9).

La sugerencia de esta nota es que tal idea consiste en el comienzo de un tiempo nuevo y mejor en la historia de España tras los siglos oscuros precedentes, exactamente lo que había llamado en el año de la Gloriosa "nuestro trabajoso renacimiento" ("Sobre el concepto" 745) ${ }^{7}$, expresión en la que cuenta tanto el nombre como su adjetivo. Tal

6 Sirvan estos ejemplos de una perspectiva y de la contraria: "la historia se presenta a los ojos de todos como única luz que puede esclarecer las vías del porvenir y como prudentísima maestra a quien incumbe el consejo en los problemas de la vida" (Historia 531), pero en otro lugar se lee: "Cada cual ve las cosas a su manera. La Historia enseña poquísimo" (Don Cristóbal 805).

${ }^{7}$ Al tratar la concepción teleológica de las historias literarias, Hutcheon hace una observación sobre los renacimientos que acaso ayude a explicar el conjunto del planteamiento sugerido por Valera: "Incluso cuando algunas de estas historias literarias nacionales han contado relatos de abandono o de declive cultural temporal, había generalmente un movimiento proyectado hacia el renacimiento, la restauración o la recuperación" (238). 
es el hilo conductor de la extensa narración con la que continuó el texto de Modesto Lafuente, la unidad de acción que concede verdadero significado al pasado objeto de exploración, o la moraleja postrera. Desde esa idea iluminadora, la percepción del romanticismo muestra su alcance real. En principio sorprende la exagerada estima con que el historiador valora globalmente los logros de los románticos, cuando en el detalle de su exposición ha subrayado no pocos reparos de gravedad. El juicio definitivo los ignora, porque el romanticismo ha de convertirse en el argumento de más peso para representar el renacimiento en cuestión, que en su conjunto sería una auténtica fe de vida nueva. El contexto trabajoso obliga a forzar la argumentación, pero no la invalida, en todo caso aporta una prueba más sobre la naturaleza artificiosa de la Historia.

\section{BIBLIOGRAFÍA}

Abad, Francisco. "Las ideas estéticas de don Juan Valera". Juan Valera. Creación y crítica. Ed. Cristóbal Cuevas García y coord. Enrique Baena. Málaga: Publicaciones del Congreso de Literatura Española Contemporánea, 1995. 65-83.

Amorós, Andrés. La obra literaria de don Juan Valera: La "música de la vida". Madrid: Castalia, 2005.

Azaña, Manuel. Vida de don Juan Valera. Ed. Antonio Martín Ezpeleta. Cabra: Ayuntamiento, 2005.

Beltrán Almería, Luis. ¿Qué es la historia literaria? Madrid: Mare Nostrum, 2007.

Bermejo Marcos, Manuel. Don Juan Valera, crítico literario. Madrid: Gredos, 1968.

Cuenca Toribio, José Manuel. "Don Juan Valera y la política: ¿Necesidad o inclinación?” Juan Valera cien años después 1905-2005. Ed. Leonardo Romero Tobar. Málaga: Junta de Andalucía, 2005. 101-19.

Díez-Canedo, Enrique. "España en los umbrales del arte moderno". El concepto contemporáneo de España. Antología de ensayos (1895-1931). Ed. Ángel del Río y M. J. Benardete. Buenos Aires: Losada, 1946. 457-70.

Gullón, Germán. El jardín interior de la burguesía. La novela moderna en España (18851902). Madrid: Biblioteca Nueva, 2003.

Hutcheon, Linda. "Repensar el modelo nacional". Naciones literarias. Ed. Dolores Romero López. Rubí - Madrid: Anthropos - Universidad Complutense, 2006. 231-304.

Lloréns, Vicente. Liberales y románticos. Una emigración española en Inglaterra (1823-1834). $3^{\mathrm{a}}$ ed. Madrid: Castalia, 1979.

Montesinos, José F. Valera o la ficción libre. Ensayo de interpretación de una anomalia literaria. Madrid: Gredos, 1957.

Onís, Federico de. "El estudio del español en los Estados Unidos". Ensayos sobre el sentido de la cultura española. Madrid: Publicaciones de la Residencia de Estudiantes, 1932. 121-79.

Romero Tobar, Leonardo. "Juan Valera, historiador". Obra histórica. Por Juan Valera. IXLXXXVI. 
Rubio Cremades, Enrique. Panorama crítico de la novela realista-naturalista española. Madrid: Castalia, 2001.

Rújula, Pedro. “Antonio Pirala y la Historia Contemporánea”. Vindicación del general Maroto y manifiesto razonado de las causas del Convenio de Vergara. Por Antonio Pirala y Criado. Pamplona: Urgoiti, 2005. XI-CXXXIII.

Sáinz Rodríguez, Pedro. Evolución de las ideas sobre la decadencia española y otros estudios de crítica literaria. Madrid: Rialp, 1962.

Sotelo Vázquez, Adolfo. "Juan Valera, observador de la novela contemporánea (1860-1904)". El arte de la novela. Por Juan Valera. Ed. Adolfo Sotelo Vázquez. Barcelona: Lumen, 1996. 9-68.

Valera, Juan. "Continuación de la Historia General de España de Modesto Lafuente". Obra histórica. Ed. Leonardo Romero Tobar. Pamplona: Urgoiti, 2004. 3-522.

Correspondencia. Volumen I (Años 1847-1861). Ed. Leonardo Romero Tobar (dir.), María Ángeles Ezama Gil y Enrique Serrano Asenjo. Madrid: Castalia, 2002.

Correspondencia. Volumen II (Años 1862-1875). Ed. Leonardo Romero Tobar (dir.), María Ángeles Ezama Gil y Enrique Serrano Asenjo. Madrid: Castalia, 2003.

Correspondencia. Volumen III (Años 1876-1883). Ed. Leonardo Romero Tobar (dir.), María Ángeles Ezama Gil y Enrique Serrano Asenjo. Madrid: Castalia, 2004.

"Del romanticismo en España y de Espronceda". Obras completas. Tomo II. Est. prel. Luis Araujo Costa. $3^{\text {a }}$ ed. Madrid: Aguilar, 1961. 7-19.

"Don Cristóbal de Moura, primer marqués de Castel-Rodrigo". Obra histórica. 801-10.

"Historia de Gibraltar y de su campo, por don Francisco María Montero". Obra histórica. 531-6.

"Plan de una historia de España y Portugal". Obra histórica. 583-95.

"Sobre el concepto que hoy se forma de España". Obras completas. Tomo III. Est. prel. Luis Araujo Costa. Madrid: Aguilar, 1958. 737-51.

White, Hayden. El contenido de la forma. Narrativa, discurso y representación histórica. Barcelona - Buenos Aires - México: Paidós, 1992.

"El texto histórico como artefacto literario". El texto histórico como artefacto literario y otros escritos. Intr. Verónica Tozzi. Barcelona - Buenos Aires - México: Paidós - I.C.E. de la Universidad Autónoma de Barcelona, 2003. 107-39. 